\title{
Ultrastructural appearances of a lens with marked polychromatic lustre: evidence for diffraction as
}

\section{a cause}

\author{
B. P. HAYES AND R. F. FISHER \\ From the Department of Visual Science, Institute of Ophthalmology, Judd Street, London WC1H $9 Q S$
}

SUmmary A human lens showing polychromatic lustre associated with cortical opacities (Christmas tree cataract) has been examined by slit-lamp photography, thin-section light microscopy, and electron microscopy. Anterior epithelial cells were fibroblast-like, and an area of breakdown of cortical lens fibres was observed in the anterior lens, containing feathery fibres, whorls, and process bodies. Parallel sided stacks of fused cell membranes were found beneath the watery area at the same depth as the polychromatic lustre seen in the slit-lamp. The dimensions of these membrane plates are consistent with the diffraction of light by a parallel thin film to give coloured points of light. Deeper areas of small granules between the lens fibres are associated with the main trunk-like opacity and its branches seen with the slit-lamp.

Polychromatic lustre observed with the slit-lamp in the living eye has often been noticed to be associated with crystalline deposits in the lens substance, seen following its extraction and subsequent dissections.' As a consequence of this the deposits have been thought to be the cause of the lustre. Indeed Bunge ${ }^{2}$ suggested that the most likely crystalline substance associated with this effect was cholesterol. Feldman ${ }^{3}$ pointed out that, although polychromatic lustre was sometimes seen in early cataract, there was no evidence that the cholesterol content of the lens was increased.

The present observations relate to a case of striking polychromatic lustre associated with branching opacities within the cortical substance of the lens. This is an example of a rare form of cataract in elderly patients and because of its striking appearance has been termed 'Christmas tree cataract.' The branching grey opacities arise from a central larger core and thus resemble branches, while the coloured points of light give an appearance of coloured lights decorating these branches, as on a Christmas tree. So far as we are aware the ultrastructure of this type of cataract has not previously been examined, although many of the fine structural changes which accompany aging are known. ${ }^{4}$

Correspondence to Professor R. F. Fisher.
In this study slit-lamp photography and light and electron microscopy are used to identify the structures responsible for Christmas tree cataract. The fine structure of the lens is compared to that of normal lenses ${ }^{5}$ and other types of cataract.

Materials and methods

\section{CASE REPORT}

The patient was an 85-year-old female complaining of gradual reduction in vision over the past five years. The ophthalmic history was unremarkable, but she had a colostomy performed three years previously following the removal of a large bowel tumour.

\section{OPHTHALMIC EXAMINATION}

On admission to hospital for cataract surgery the patient's vision was: right eye $6 / 60$ and left eye eye counting fingers. These visual acuities were not improved with lenses. Apparently normal fundi were imperfectly seen in both eyes, though the cataract was obviously more advanced in the left eye.

\section{LIGHT AND ELECTRON MICROSCOPY}

Whole lenses were fixed by immersion in $3 \%$ glutaraldehyde in phosphate buffer and postfixed in 1\% $\mathrm{OsO}_{4}$ in White's solution. ${ }^{6}$ The lenses were bisected through the lens axis, block stained in uranyl acetate, 


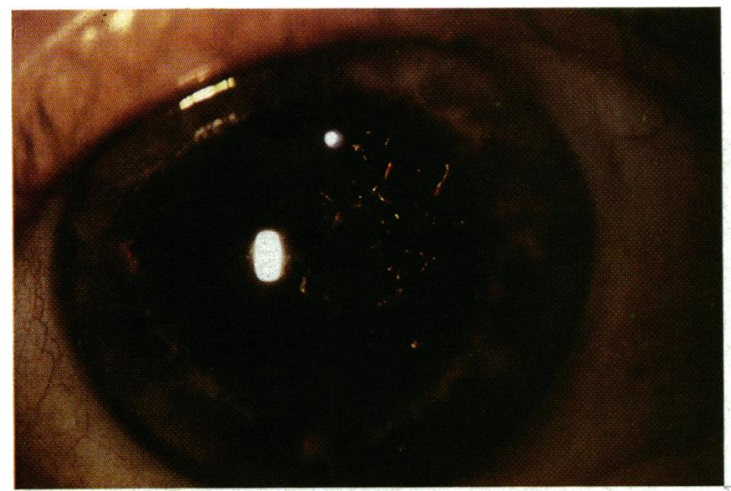

Fig. 1a Slit-lamp view of right eye.

dehydrated, and embedded in Araldite. Light and electron microscope sections were cut approximately perpendicular to the surface of the lens in the region of the anterior cortex. Light microscope sections were stained with $1 \%$ toluidine blue/borax, and electron microscope sections with ethanolic uranyl acetate and alkaline lead citrate. Measurements of electron microscope negatives were made at $\mathbf{8 0 0 0 0}$ magnification after calibrating the microscope with negatively stained catalase specimens. ${ }^{7}$

\section{Results}

\section{CATARACT APPEARANCES}

The striking slit-lamp appearances of the cataracts in this patient are shown in Figs. 1a and $b$. The beautiful interplay of colours arising from the anterior cortical substance of the lenses is about $0.5 \mathrm{~mm}$ from the anterior surface of the lens. The colours are more obvious in the right eye, but the left eye subsequently had a cataract extraction and provided the lens specimen for ultramicroscopic examination. The less obvious polychromatic lustre (Fig. 1b) in this eye appeared to be due to a greater scatter from more advanced cataractous changes present in the nucleus of this lens.

MEASUREMENT OF SIZE OF COLOURED AREAS An estimate of the size of the coloured areas was made by first comparing the corrected pupil diameter with its diameter seen in the photographs. With this estimate of the scale magnification of the colour transparency the coloured areas were measured by observing them with a microscope containing a ruled graticule in the eyepiece. The mean diameter of the areas of polychromatic lustre varied considerably because of variation in shape: some areas were round while others were comma-shaped or rectangular (Figs. 1a and b). However, from measurements of

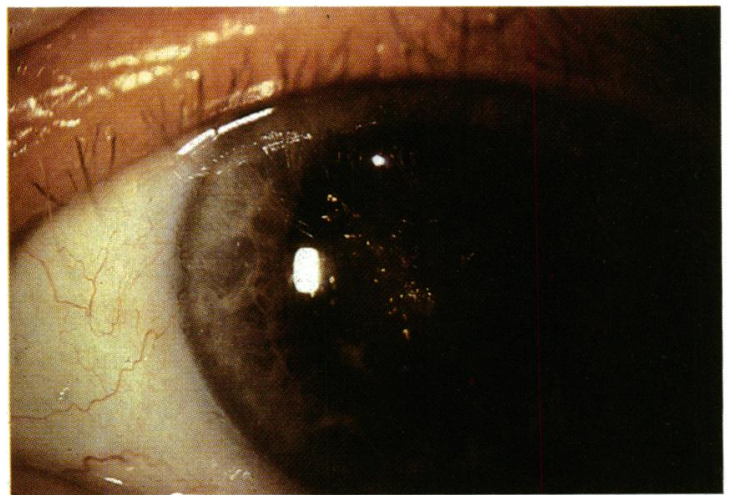

Fig. 1b Slit-lamp view of left eye from which cataract was removed.

the colour photographs the apparent mean diameter was $2 \cdot 03 \pm 0.68 \mu \mathrm{m}$.

LIGHT AND ELECTRON MICROSCOPY OF

BRANCHING PORTION OF CATARACT

Deep within the cortex, about $725 \mu \mathrm{m}$ below the surface of the lens, an area of disruption of lens fibres was found between the shrunken densely stained lens fibres (Fig. 2a). This consisted of a thick trunk $(40 \mu \mathrm{m}$ thick) parallel to the lens surface, and its more slender branches extending superficially to $625 \mu \mathrm{m}$ depth. The trunk extended from the equator to the lens axis at $725 \mu \mathrm{m}$ depth on one side of the lens only. Both the main trunk and its branches were packed with small rounded granules $(0 \cdot 1-0 \cdot 5 \mu \mathrm{m}$ diameter) and with interdigitating lens fibre processes of similar diameter (Fig. 2b). In addition the main trunk contained larger granules of up to $10 \mu \mathrm{m}$ diameter (Fig. 2a). No organelles that appeared capable of producing polychromatic lustre were found in this deep area of disruption of the lens cortex.

\section{EPITHELIAL AND CORTICAL CHANGES}

Areas presumed to produce polychromatic lustre were found in the anterior lens cortex at some distance from the branching area. This distance was, however, too small to be separated by slit-lamp appearances. The coloured lights were therefore not quite on the branches of the tree, as had appeared from the slit-lamp observations.

\section{LIGHT AND ELECTRON MICROSCOPY OF THE}

ANTERIOR LENS

The lens capsule was of normal ultrastructure and thickness (about $17 \mu \mathrm{m}$ thick at the anterior pole). The epithelium was thin and discontinuous in the region of the anterior pole, where there were patches of darkly stained spindle-shaped epithelial cells overlying a watery area of lens cortex (Fig. 3a). Towards 

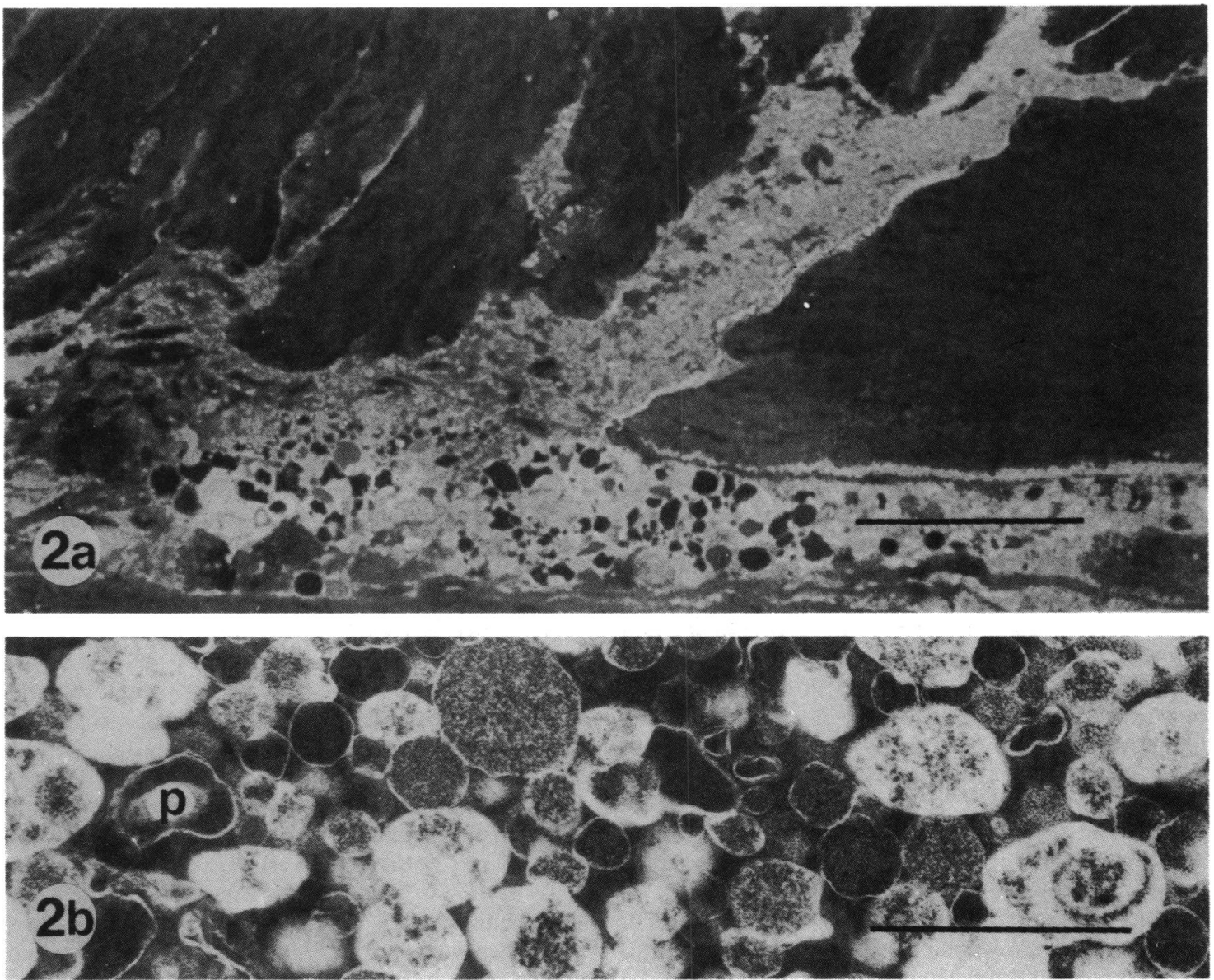

Figs. 2a and b Branching portion of the cataract. a: Light micrograph of the deep area of disruption of the cortical lens fibres. The area consists of a main trunk parallel to the lens surface containing large granules (up to $10 \mu \mathrm{m}$ diameter) at $725 \mu \mathrm{m}$ depth. Slender branches extend superficially and contain smaller granules below the resolution of the light microscope. $(\times 260$; scale line $100 \mu \mathrm{m})$. b: Small granules (0.1-0.5 $\mu \mathrm{m}$ diameter) found in the main trunk and branches of the area shown in Fig. 3. Interdigitating lens fibre processes $(\mathrm{p})$ can also be seen. $(\times 30000$; scale line $1 \mathrm{um})$.

the equator, where the lens cortex showed less disruption, the epithelium had a more normal appearance and dimensions (thickness $6.5 \mu \mathrm{m}$ ), though small vacuoles were found in the cytoplasm adjacent to the capsule, and a few small membrane whorls were present.

An area of liquefaction of the superficial cortical lens fibres was seen, $500 \mu \mathrm{m}$ deep at the anterior pole and $250 \mu \mathrm{m}$ deep towards the equator (Fig. 3a). At the pole this area contained feathery fibres about 0.5 $\mu \mathrm{m}$ diameter mainly orientated parallel to the surface of the lens; these had a fine granular cytoplasmic matrix like that of normal lens fibres. The matrix of the watery area was also like that of lens fibres, but more loosely arranged (Fig. 3b). The watery area contained very swollen lens fibres (maximum diameter $20 \mu \mathrm{m}$ ), and also more shrunken fibres with swollen tips (Fig. 3a). The swollen fibres were palely stained and bounded by cell membrane with junctional complexes to adjacent swollen fibres (Fig. 3b). Dense granules $(0 \cdot 1-1.5 \mu \mathrm{m}$ diameter) were also found in the watery area (Fig. 4a). In the deepest part of the watery area whorls and flattened stacks of fused membranes were found in the watery matrix and within the swollen lens fibres (Fig. 4a). We have called the flattened stacks of membranes 'membrane plates.' Occasionally very large membrane whorls ( 5 $\mu \mathrm{m}$ diameters) and dense bodies (6 $\mu \mathrm{m}$ diameter) containing many interleaved electron lucent processes were seen in the deep part of the watery area (Fig. 4b). Deep to the watery area of lens cortex a 20 $\mu \mathrm{m}$ thick zone of swollen lens fibres orientated 

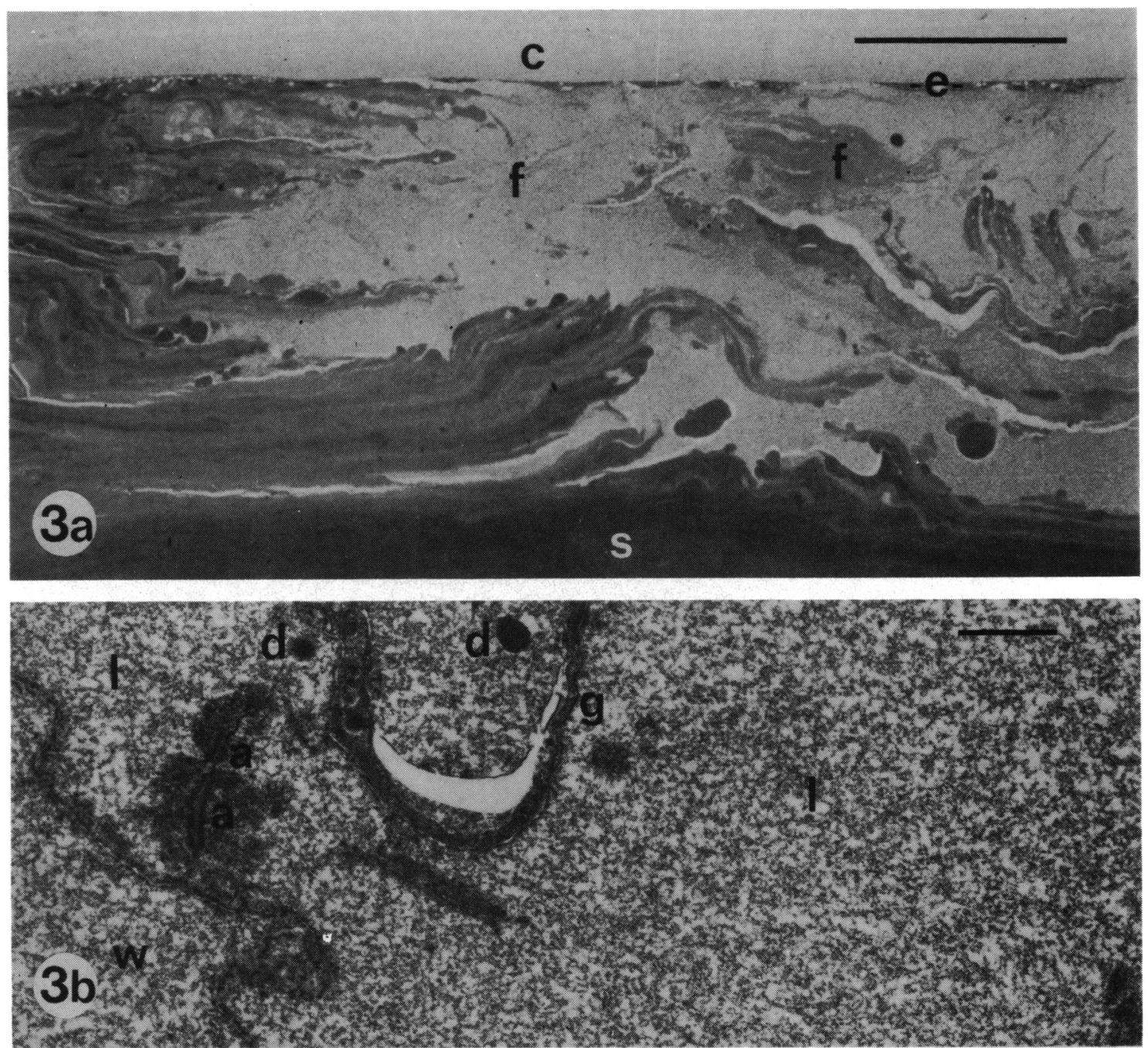

Fig.s 3a and b Anterior watery area of the lens. a: 1 um light microscope section of the capsule (c), epithelium (e), and lens cortex in the region of the anterior pole. Discontinuous spindle-shaped epithelial cells are present. The watery area of the lens cortex contains fibres showing swelling, shrinkage, and dense granules. Feathery fibres are also found here (f). Beneath the watery area fibres are shrunken and darkly stained $(\mathrm{s}) .(\times 260 ;$ scale line $100 \mu \mathrm{m})$. b: Swollen lens fibres $(1)$ in the watery area of anterior cortex make gap (g) and adhering (a) cell junctions. The lens fibre matrix is of loosely arranged granular material like the matrix of the watery area $(\mathrm{w})$ and contains small dense granules $(\mathrm{d}) .(\times 12000$; scale line $1 \mu \mathrm{m})$.

parallel to the lens surface was found (Fig. 4a). Membrane whorls, membrane plates, and dense granules were common in this zone.

The simplest form of membrane inclusion capable of producing polychromatic lustre (see 'Discussion'), found in the lens cortex, was a flattened stack of fused parallel membranes, consisting of electron dense lamellae spaced at a $4.7 \mathrm{~nm}$ periodicity (Fig. $5 \mathrm{a}$ ). These membrane plates varied in thickness between 25 and $150 \mathrm{~nm}$, and in diameter between 0.2 and 3 $\mu \mathrm{m}$, and their long axes were usually parallel to the lens surface. The plates were not found singly but in a branched configuration (Fig. 5a). Membrane plates, and more elaborate granules containing these plates, were found only in the deep water cleft and underlying lens fibres, at depths of 300 to $500 \mu \mathrm{m}$ below the surface of the lens. In the more complex bodies the plates radiated from a centre within a swollen lens fibre, but the majority still lay parallel to the surface of the lens; such membranous bodies were about 5 

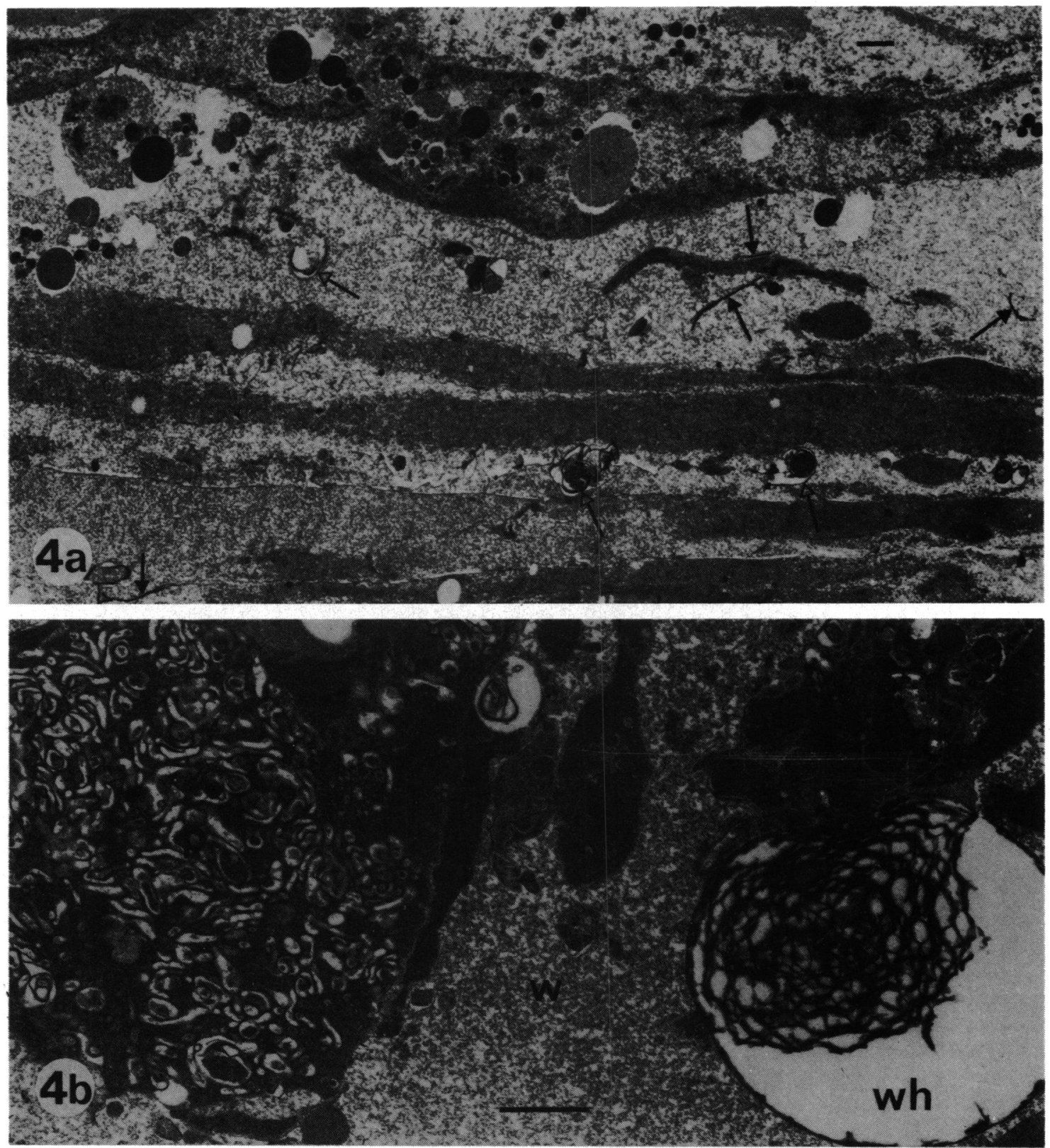

Figs. 4a and b Deep zone of the watery anterior cortex (about $350 \mu \mathrm{m}$ below the surface of the lens. a: Dense granules, swollen fibres, and membrane plates (arrows) are present in the watery area. Membrane plates and whorls (open arrows) are found between the swollen lens fibres beneath the watery area. ( $\times 5000 ;$ scale line $1 \mu m)$. b: A large membrane whorl (wh, $4 \mu m$ diameter) consisting of interleaved stacks of fused membrane is present; the separation between the boundary and internal membranes may be a preparation artefact. A process body (p, 5.3 $\mu \mathrm{m}$ diameter) contains a mosaic of electron lucent processes in a dense matrix. $w=$ Matrix of the watery area. $(\times 12000$; scale line $I \mu \mathrm{m})$.

$\mu \mathrm{m}$ diameter (Fig. 5b). Sometimes membrane plates encircled the interdigitating processes of lens fibres.

Lens fibres at greater depth in the cortex were densely stained and shrunken (minimum diameter $0 \cdot 1 \mu \mathrm{m}$ ) and were linked by numerous ball and socket interdigitations. The most complex arrangement 

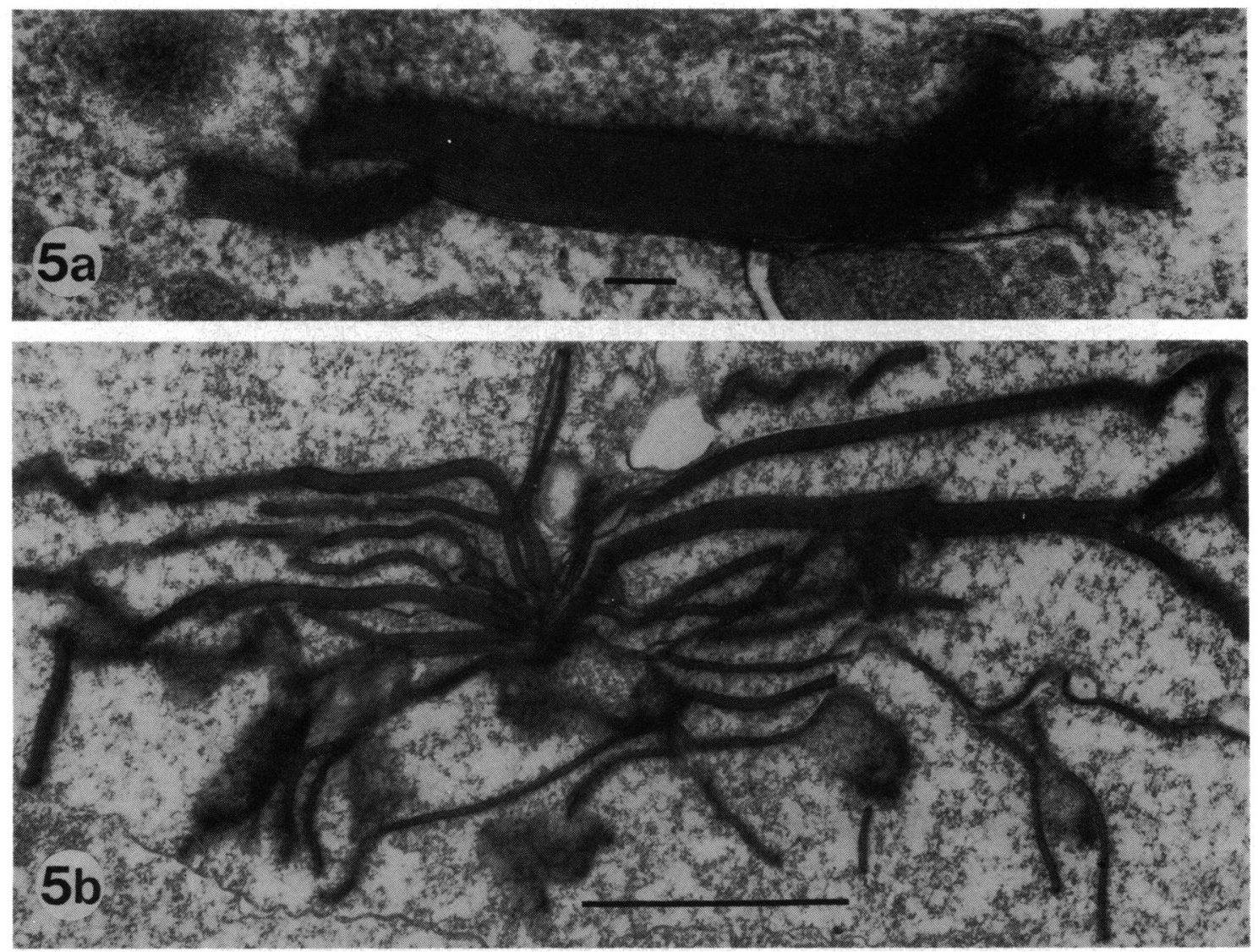

Figs. 5a and b Membrane plates. a: Simple membrane plate found in the zone of swollen lens fibres beneath the watery area. Thickness of the main plate is $144 \mathrm{~nm}$ and diameter $1 \mu \mathrm{m}$. Orientation is parallel to the surface of the lens. Periodicity of membrane lamellae $4.7 \mathrm{~nm}$. The edges of the plate are continuous with the lens fibre cell membrane. $(\times 80000 ;$ scale line 0.1 $\mu \mathrm{m})$. b: Complex branching network of membrane plates radiating from a central core, in the same zone as Fig. $5 a$. Plate thickness is from 30 to $117 \mathrm{~nm}$ and diameter $0 \cdot 2$ to $2 \cdot 7 \mu \mathrm{m}$. Predominant orientation of the plates is parallel to the lens surface. ( $\times 30000$; scale line $1 \mu \mathrm{m})$.

of membrane plates was found here between the shrunken fibres, in bodies of up to $9 \mu \mathrm{m}$ diameter (Fig. 6a). These bodies contained membrane plates radiating from a central core and separated by small tongues of lens fibre cytoplasm (Fig. 6a). Cell membranes within these bodies were less electron dense than in the simpler membrane plates and their periodicity was wider and more variable $(5-7 \mathrm{~nm})$ (Fig. 6b). The maximum thickness of membrane plates within the complex bodies was $330 \mathrm{~nm}$.

Occasionally lens fibre interdigitations were mixed with concentric layers or fused membrane to give large whorl-like granules approximately $5 \mu \mathrm{m}$ in diameter between the shrunken lens fibres. Sometimes the processes within such a granule were dense and spicule-like in section and embedded in a lightly stained striated matrix of periodicity approximately
$4.6 \mathrm{~nm}$ (Fig. $6 \mathrm{c}$ ). The dimensions of these striations were too small to produce polychromatic lustre.

No crystals of any kind were found in the lens.

\section{Discussion}

Comparison of the fine structure of the cataractous lens with the normal human lens ${ }^{45}$ demonstrates changes in the lens epithelium and anterior cortex. The anterior epithelium is thin and discontinuous, consisting of cells which are spindle-shaped in crosssection. We had previously observed such an appearance in radiation cataract, ${ }^{6}$ but degeneration of the epithelium is also associated with aging of the lens, ${ }^{8}$ as seems to be the case here.

An area of cortical liquefaction was found in the anterior lens immediately beneath the patchy epi- 

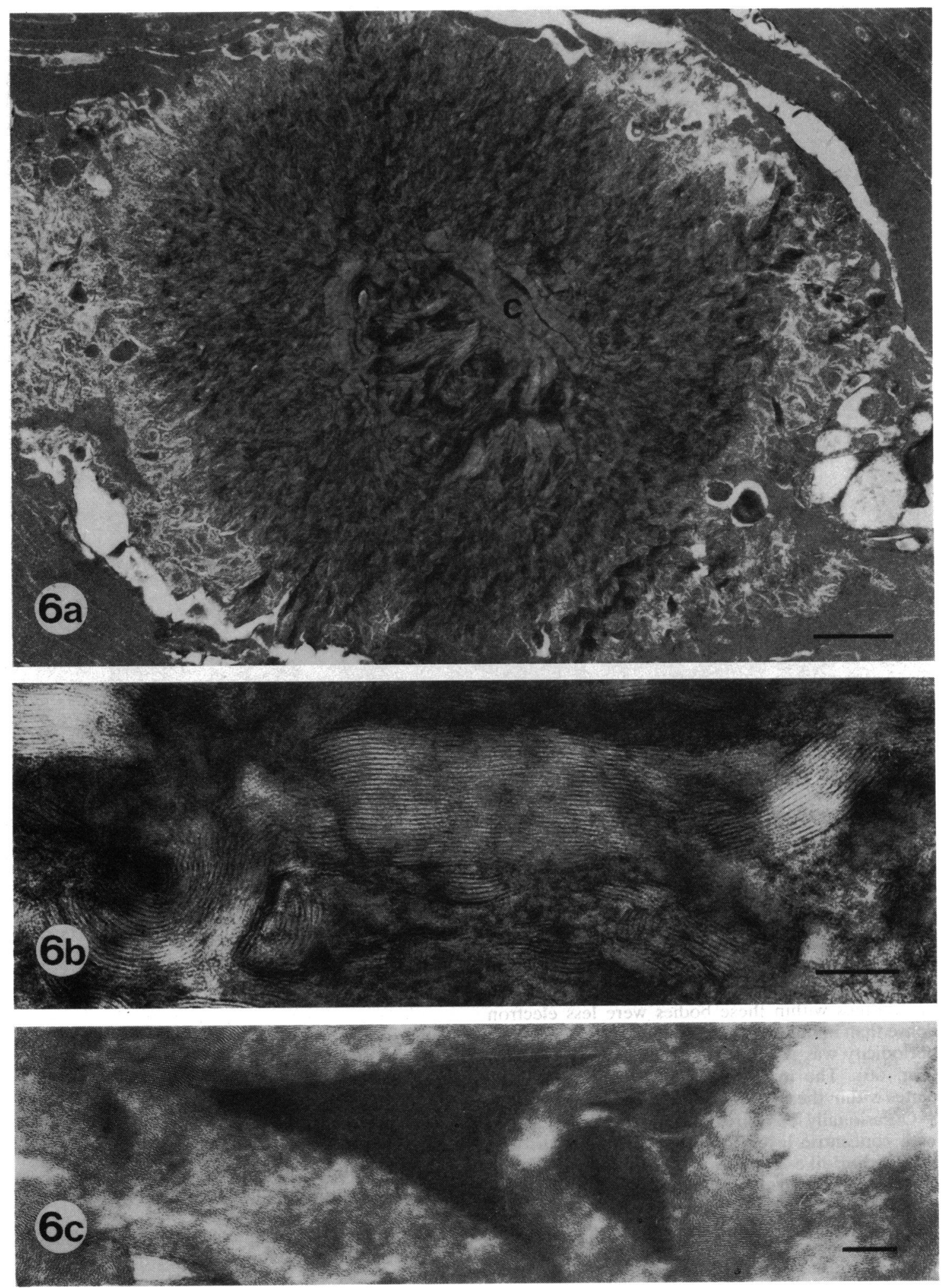

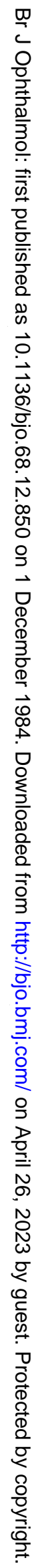


thelium. The changes of structure of the cortex found here are also like those in radiation cataract. ${ }^{6}$ At the edge of the watery area fibres shrink, their cell membranes break, their tips swell, and dense granules are formed. The watery area contains the products of this lens fibre degeneration: swollen fibres, dense granules, and the misaligned feathery fibres which were first described in radiation cataract. ${ }^{6}$ In the deepest part of the watery area membrane whorls and dense bodies containinz a mosaic of interdigitating processes are found. Similar organelles have been described in senile cataract." Dense granules found here may be the beginning of the morgagnian globules present in more mature cortical cataract. ${ }^{10}$

A new type of inclusion, the membrane plate, has been found at the junction of the watery area and the deeper more intact lens cortex, that is, at a depth of 300-500 $\mu \mathrm{m}$ below the anterior surface of the lens. This is the depth at which the interplay of colours is seen in the slit-lamp. Membrane plates are parallel sided stacks of fused cell membrane 25-150 nm thick which may arise by passive degenerative fusion of cell membranes. They are usually orientated parallel to the surface of the lens. Since they are made up of cell membrane rather than lens proteins we would expect their refractive index to be different from that of the surrounding lens fibre matrix. This is because basement membrane (capsule) contains about $15 \%$ more water than lens fibre protein, so one would expect the membranes to have a lower refractive index. Assuming these differences in refractive index, the thickness and parallel sides of the membrane plates are consistent with the production of polychromatic lustre through diffraction of light by a parallel thin film. The theoretical considerations are dealt with later in the discussion. Further evidence for the membrane plates as a source of polychromatic lustre is provided by their similarity in diameter to the coloured areas seen in the slit-lamp.

More complex bodies incorporating many membrane plates radiating from a central core were found among the intact lens fibres just below the water cleft. Although the thickness and diameter of individual plates within these bodies is still consistent with the polychromatic effect, their more disorganised arrangement might be expected to result in an opaque rather than a coloured area. It is unlikely that the polychromatic lustre is due to the presence of cholesterol crystals, ${ }^{2}$ since no crystals were found in the lens.

A deep area of disruption of the anterior cortex was found about $725 \mu \mathrm{m}$ below the surface: this area might correspond to the deeper area of light scatter seen in the slit-lamp. Both the main trunk and branches of this area were packed with small granules. Such an accumulation of granules has been described in senile cataract. ${ }^{4}$

\section{THEORETICAL THICKNESS OF COLOURED AREAS WITHIN THE LENS}

If it is allowed that the coloured areas seen in the cortex of the lens (Figs. 1a and b) are due to diffraction effects similar to those produced by the minute scales on the wings of butterflies, it is possible to calculate the minimum thickness of such an area. From the theory of diffraction of light by a parallel thin film we have:

$$
t=\frac{(n+1 / 2) \lambda}{2 \mu \cos r}
$$

where $t$ is the thickness of the film (nm), $\lambda$ is the wavelength of light $(\mathrm{nm}), r$ is the angle of refraction (degrees) and $\mu$ is the refractive index of the film in relation to its surroundings. A minimum value of $t$ occurs when $n=0$ and $r=0$. Thus: $t_{m}=$

$$
\frac{\lambda}{4 \mu}
$$

where $t_{m}$ is the minimum thickness of film (nm). In the present circumstances the value of the refractive index is slightly above or below unity. It is more likely to be less than unity $(0.9914)$, since the refractive index of lens cortex in air is about $1.385^{11}$ and the refractive index of lens capsule (basement membrane) is little greater than water. ${ }^{12}$ If the parallel sided film is of lower refractive index than the cortical lens substance, the half wavelength phase change in the light occurs at the deeper film surfaces, and the minimum thickness of a film to give a polychromatic lustre lies between 125 and $165 \mathrm{~nm}$.

These theoretical values are in good agreement with those observed by electron microscopy (25$150 \mathrm{~nm})$.

Figs. 6a-c Lens cortex deep to the watery area. a: A complex granule (8.9 um diameter) containing membrane plates, among shrunken lens fibres deep to the watery area, depth 400 um approximately. The central core (c) contains large plates, up to 200 $n m$ thick and 2.5 um diameter. Many small interleaved plates radiate from the core. The interdigitating processes of lens fibres are found at the edge of the granule. $(\times 12000$; scale line $1 \mu \mathrm{m})$. b: Central region of a complex granule like that shown in Fig. $6 a$. The central membrane plate is 5 um long and $167 \mathrm{~nm}$ thick, with a $5.6 \mathrm{~nm}$ periodicity of the membrane lamellae. Many smaller, interleaved membrane plates surround the core and are separated by narrow tongues of lens fibre cytoplasm. $(\times 126000 ;$ scale line $0 \cdot 1 \mu \mathrm{m})$. c: Spicule-like lens fibre processes within a large granule, deep to the watery area. The matrix of the granule shows $4.6 \mathrm{~nm}$ striations. $(\times 80000$; scale line $0.1 \mu \mathrm{m})$. 
We thank Mr C. Townsend, FRCS, Western Ophthalmic Hospital, for kindly allowing us to examine the patient, Miss S. Ford, Western Ophthalmic Hospital, for Figs. 1 and 2, Mr D. Goulding for technical assistance, and the Wellcome Trust for an apparatus grant.

\section{References}

1 Duke-Elder S. Diseases of the lens and vitreous, glaucoma and hypotony. System of ophthalmology. London: Kimpton, 1969; 11: $131-4$.

2 Bunge E. Zum histologischen Cholesterinnachweis bei verschiedenen Trubungsformen der menschlichen Linse. Arch Augenheilkd 1936; 109: 503-53.

3 Feldman GL. In: Dardenne MV, Nordmann J, eds. Biochemistry of the eye. Basel: Karger, 1968: 348.

4 Kobayashi Y, Suzuki T. The aging lens: ultrastructural changes in cataract. In: Bellows JG, ed. Cataract and abnormalities of the lens. New York: Grune and Stratton, 1975: 313-43.

5 Hogan MJ, Alvarado JA, Weddell JE. Histology of the human eye. Philadelphia: Saunders, 1971: 638-77.
6 Hayes BP, Fisher RF. Influence of a prolonged period of low-dosage $x$-rays on the optic and ultrastructural appearances of cataract of the human lens. Br J Ophthalmol 1979; 63: 457-64.

7 Fisher RF, Hayes BP. Ultrastructure and elastic changes of regenerated basement membrane in normal and diabetic rats. $B r$ J Exp Pathol 1982; 63: 341-50.

8 Yanoff M. Pathology of cataract. In: Bellows JG, ed. Cataract and abnormalities of the lens. New York: Grune and Stratton, 1975: 155-89.

9 Brini A, Porte A, Stoekel ME. Modifications ultrastructurals du crystallin dans certaines cataractes expérimentales et humaines. Bull Mem Soc Fr Ophthalmol 1963; 76: 193-208.

10 Hogan MJ, Zimmerman LE. Ophthalmic pathology. Philadelphia: Saunders, 1962: 682-3.

11 Duke-Elder S. Ophthalmic optics and refraction. System of ophthalmology. London: Kimpton, 1970; 5: 134.

12 Fisher RF. The water permeability of basement membrane under increasing pressure-evidence for a new theory of permeability. Proc R Soc Lond (Biol) 1982; 216: 475-96. 